\title{
The effect of Daclizumab in a high-risk renal transplant population
}

Meier-Kriesche H-U, Kaza H, Palekar SS, Friedman GS, Mulgaonkar SP, Ojo AO, Kaplan B. The effect of Daclizumab in a high-risk renal transplant population.

Clin Transplantation 2000: 14: 509-513. C Munksgaard, 2000

Abstract: Introduction: African-American (AA) renal transplant recipients have a higher incidence of acute rejection when compared to Caucasian renal transplant recipients. This higher rejection rate holds true even with the addition of several of the newer immunosuppressive agents (e.g. mycophenolate mofetil (MMF) and Rapamycin). Acute rejection rates among Hispanic $(\mathrm{H})$ renal transplant recipients are higher in some settings, while lower or the same as in Caucasians in other settings. IL-2 receptor antibodies have been shown to decrease rejection rates when added to a regimen of cyclosporine (CsA), azathioprine and prednisone. Limited data are available on these agents in conjunction with triple CsA, MMF and prednisone therapy, particularly in higher risk group patients. We studied the effect of the addition of the IL-2 receptor antibody Daclizumab to a CsA, MMF, prednisone regimen in a group of African-American and high-risk Hispanic renal transplant recipients.

Methods: This was a non-randomized, prospective study. A total of 49 renal transplant recipients (29 African-American and 20 Hispanic) were studied and followed. A simultaneous cohort of 56 (31 AfricanAmerican and 25 Hispanic) renal transplant recipients receiving CsA, MMF and prednisone with no standard induction agent served as the control group. The study cohort received the same regimen with the addition of Daclizumab at $1 \mathrm{mg} / \mathrm{kg}$ for five doses over $10 \mathrm{wk}$. Multivariate analysis was performed to isolate independent factors influencing the study's results.

Results: A total of 56 patients in the control group and 49 patients in the Daclizumab group received an average follow-up of $17.1 \pm 6.9$ and $12.7 \pm 5.1$ months, respectively. Acute rejection rates were lower in the Daclizumab group as compared to the control group $26.4 \%$ versus $49.3 \%$ per patient years, respectively. A total of eight recurrent rejections in 6 patients occurred in the control group and none in the Daclizumab arm. Graft loss at this follow-up was no different between the groups.

Conclusion: The addition of Daclizumab to a regimen of CsA, MMF and prednisone decreases acute rejection episodes in a high-risk group of African-American and Hispanic renal transplant recipients.

\author{
Herwig-Ulf Meier-Kriesche ${ }^{a}$, \\ Harsha Kazab ${ }^{\mathrm{b}}$, Sadanand \\ S Palekarc, Gary S Friedman ${ }^{\mathrm{b}}$, \\ Shamkant P Mulgaonkarb, \\ Akinlolu $O$ Ojo $^{\mathrm{a}}$ and \\ Bruce Kaplan $^{\mathrm{a}}$ \\ a Department of Internal Medicine, \\ University of Michigan, Ann Arbor, Ml, \\ ${ }^{b}$ Department of Transplantation, Saint \\ Barnabas Medical Center, Livingston, NJ, \\ ${ }^{c}$ Department of Transplantation, Newark \\ Beth Israel Medical Center, 201 Lyons \\ Avenue, Newark, NJ, USA
}

Key words: African-American -

Daclizumab - high risk - Hispanic immunosuppression - induction - kidney transplantation

Corresponding author: Bruce Kaplan, MD, The University of Michigan Medical Center, Department of Internal Medicine, 3914 Taubman Center, Box 0364, Ann Arbor, Ml 48109-0364, USA. Tel: + 1 (734) 9365645; fax: + 1 (734) 936-9621; e-mail: brkaplan@umich.edu

Accepted for publication 5 June 2000
It is well recognized that African-American (AA) renal transplant recipients have an increased incidence of acute rejection when compared to Caucasian patients $(1-3)$. The recent approval of agents, e.g. mycophenolate mofetil (MMF), tacrolimus and Rapamycin, have all decreased acute rejection rates when compared to their con- trol group (4-6). However, each of these studies demonstrated either higher rejection rates or need for higher drug dosages in African-American patients $(7-10)$.

The use of antibody induction in reducing rejection in high-risk patients such as African-American renal transplant recipients has been addressed 
in previous studies with generally favorable results (11-13). However, these studies only evaluated polyclonal anti-lymphocytic antibodies or OKT3. In addition, none of these studies addressed the effect of antibody induction when added to regimens utilizing newer immunosuppressive agents such as MMF.

Daclizumab is a humanized IgG monoclonal antibody that binds to the alpha chain of the IL-2 receptor (14-16). Phase III trials utilizing Daclizumab in a regimen of cyclosporine (CsA), with or without azathioprine, and prednisone demonstrated a significant decrease in early acute rejection episodes (14-16). However, limited information is available on the efficacy of Daclizumab in African-American renal transplant recipients, particularly in conjunction with MMF therapy.

Due to the heterogeneity of the population identified as Hispanic, it has been difficult to assess this group's risk status. In our own program we noted that our Hispanic population suffered acute rejection rates higher than Caucasians and similar to that of African-Americans (45\% in AfricanAmericans and Hispanics versus $25 \%$ in Caucasians). This higher acute rejection rate in African-American and Hispanic renal transplant recipients was in the setting of a no-induction CsA, MMF and prednisone regimen.

We therefore studied the effect of the addition of Daclizumab to a regimen of CsA, MMF and prednisone in this high-risk group of renal transplant recipients.

\section{Materials and methods}

A total of 49 African-American and Hispanic renal transplant recipients constituted the study group. A simultaneous cohort of patients (56 African-American and Hispanics) was used as the control group. Study and control patients were transplanted between January 1998 and October 1999 and followed until February 2000. The control group received a regimen of calcineurin inhibitor, along with $\mathrm{MMF}$ at $1 \mathrm{~g}$ b.i.d. and solumedrol starting at $250 \mathrm{mg}$ i.v. once a day for the first 3 days and then prednisone tapered to 10 $\mathrm{mg}$ once a day by 3 months. Cyclosporine 12-h trough levels were targeted to be $250-350 \mathrm{ng} / \mathrm{mL}$ (by monoclonal TDX) during the first 3 months and then 200-300 for the rest of the year. The study group of 49 patients received an identical protocol with the exception of the addition of Daclizumab at $1 \mathrm{mg} / \mathrm{kg}$ per dose given every $2 \mathrm{wk}$ for a total of five doses over an 8-wk time period. All 49 patients completed the full course of Da- clizumab treatment. In both cohorts, all patients received the micro-emulsion formulation of CsA with the exception of 9 patients in each group who received tacrolimus-based therapy. All patients in both cohorts received trimethoprim-sulfamethoxazole for pneumocystis carinii prophylaxis and acyclovir at $800 \mathrm{mg}$ b.i.d. for cytomegalovirus (CMV) prophylaxis. Independent sample t-test, chi-square test as appropriate compared the demographic characteristics between the two groups. The rejection free survival in the two study cohorts was displayed by Kaplan-Meier survival curves. Differences in rejection free survival curves were estimated by the Breslow test. Additionally, in a multivariate approach, a Cox Proportional Hazard regression was used to estimate the independent effect of Daclizumab therapy on the development of acute rejection in the two study cohorts while controlling for relevant risk factors. This model corrected for potential confounding variables such as race, gender, diabetes, HLA mismatch, cold ischemia time, primary non-function, and donor type (living/cadaveric). Test results were considered statistically significant at $p<0.05$. All statistical analysis was performed using SPSS software (Version 9.0 for Windows 95, SPSS, Inc., Chicago, IL, USA).

\section{Results}

As demonstrated in Table 1, the baseline demographics were not significantly different between the two cohorts with exception for a higher percentage of PRA prior to transplantation in the Daclizumab group, and a significantly longer follow-up in the control group. There was a lower

Table 1. Demographics

\begin{tabular}{|c|c|c|c|}
\hline & Daclizumab $(n=49)$ & Controls $(n=56)$ & $\mathrm{p}$ \\
\hline Age (yr) & $42.8 \pm 11.2,21-65$ & $40.1 \pm 14.8,27-67$ & $n s^{a}$ \\
\hline $\begin{array}{l}\text { Gender } \\
\quad \text { (male/female) }\end{array}$ & $29 / 20(59 \%)$ & $32 / 24(57 \%)$ & $n s^{b}$ \\
\hline Race $(\mathrm{AA} / \mathrm{H})$ & $29 / 20(59 \%)$ & $31 / 25(54 \%)$ & $n s^{b}$ \\
\hline Diabetes (yes/no) & $11 / 45(16 \%)$ & $4 / 14(20 \%)$ & $n s^{b}$ \\
\hline Repeat tx (yes/no) & $8 / 41(16 \%)$ & $9 / 47(16 \%)$ & $n s^{b}$ \\
\hline Donor (LD/CAD) & $11 / 38(22 \%)$ & 22/34 (39\%) & $n s^{b}$ \\
\hline Induction (yes/no) & $13 / 36(27 \%)$ & $19 / 37(34 \%)$ & $n s^{b}$ \\
\hline Fk506/CsA & $9 / 40(18 \%)$ & $9 / 47(16 \%)$ & $n s^{b}$ \\
\hline $\mathrm{AB}$ mismatch & $1.93 \pm 1.2,0-4$ & $2.16 \pm 1.3,0-4$ & $\mathrm{~ns}^{\mathrm{a}}$ \\
\hline DR mismatch & $0.81 \pm 0.74,0-2$ & $0.89 \pm 0.71,0-2$ & $n s^{a}$ \\
\hline PRA\% & $22.8 \pm 31,0-98$ & $1.5 \pm 7.4,0-49$ & $<0.05^{\mathrm{a}}$ \\
\hline Cold ischemia (h) & $14.7 \pm 8.1,1-31$ & $13.2 \pm 11.8,0.5-37.5$ & $\mathrm{~ns}^{\mathrm{a}}$ \\
\hline DGF (yes/no) & $18 / 31(37 \%)$ & $13 / 43(23 \%)$ & $n s^{b}$ \\
\hline Follow-up (months) & $12.7 \pm 5.1,5-24$ & $17.1 \pm 6.9,5-24$ & $<0.05^{a}$ \\
\hline
\end{tabular}

\footnotetext{
a Independent sample t-test.
}

${ }^{\mathrm{b}}$ Chi-square. 
Table 2. Rejection episodes

\begin{tabular}{lccl}
\hline & $\mathrm{n}$ & $\%$ & Time post-transplant \\
\hline $\begin{array}{l}\text { First rejection } \\
\text { Daclizumab }\end{array}$ & 12 & 24.5 & $5.4 \pm 4.3^{*}, 0.2-14.9$ \\
$\quad$ Control & 21 & 37.5 & $2.2 \pm 3.1^{*}, 0.2-11.1$ \\
Second rejection & & & \\
$\quad$ Daclizumab & 0 & 0 & na \\
$\quad$ Control & 6 & 10.7 & $8.4 \pm 4.9,3.9-14.9$ \\
Third rejection & & & \\
$\quad$ Daclizumab & 0 & 0 & na \\
Control & 2 & 3.6 & $15.5 \pm 3.0,13.3-17.6$ \\
\hline
\end{tabular}

${ }^{*} \mathrm{p}<0.05$ by independent sample t-test.

incidence of living as opposed to cadaver donation in the Daclizumab group (22\%) as opposed to the control group $(39 \%)$ but the difference did not reach statistical significance. There was a trend to a higher incidence of delayed graft function in the Daclizumab group (37\%) as opposed to the control group (23\%); however, this difference was not statistically significant.

As shown in Table 2, there was a total of 12 rejections in the Daclizumab group as opposed to 29 in the control group. Of the 29 rejection episodes in the control group 21 where first rejections $(37.5 \%)$, six were repeat rejections $(10.7 \%)$ at least 3 months after the first episode, and two were third rejections. In the Daclizumab group none of the patients experienced a repeat rejection. First rejection episodes occurred significantly earlier in the control patients $(2.2 \pm 3.1$ months post-transplant) as opposed to in the Daclizumab treated patients $(5.4 \pm 4.3$ months post-transplant, $\mathrm{p}<$ $0.05)$.

As shown in Table 3, during the first year of follow-up, 11 rejection episodes $(26.4 \%$ per 100 patient years) occurred in the Daclizumab group as compared to 25 rejection episodes $(49.3 \%$ per 100 patient years) in the control group.

Fig. 1 shows that the Daclizumab group had a significantly higher rejection free survival as compared to the control group. There was also a significantly higher incidence of repeat rejections in the control group as compared to the Daclizumab group by Kaplan-Meier analysis as shown in Fig. 1.

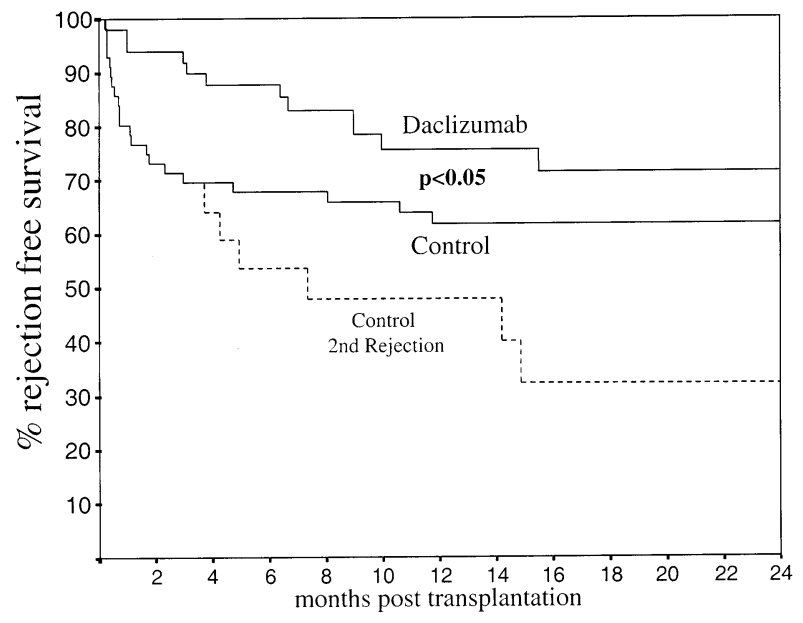

Fig. 1. Rejection free survival for first and second rejection.

Fig. 2 shows that the cumulative risk for a first rejection episode was significantly lower in the Daclizumab-treated group by Cox proportional hazard analysis. The only two significant protective factors from first acute rejection by Cox proportional hazard model were Daclizumab therapy (RR 0.34, CI 0.12-0.94) and living donation (RR $0.34,0.11-0.99)$.

\section{Discussion}

To our knowledge, this is the largest study to assess the efficacy of the addition of an IL-2 receptor antibody to a-MMF based triple therapy regimen in a high immunologic risk population. In this population of African-American and high-risk Hispanic renal transplant recipients, the addition of Daclizumab for a 10 -wk/five-dose course was associated with a significantly improved rejection free survival as compared to the control group by Kaplan-Meier analysis. The number of patients with an acute rejection episode trended lower in the Daclizumab group than in the control group $(24.5 \%$ vs. $37.5 \%)$. However, when the total number of rejection episodes was taken into account a clear superiority in event free survival was noted in the Daclizumab group. It is interesting to note that at the time of this follow-up, eight recurrent rejections have occurred in the control group and none in the Daclizumab group.

Table 3. Total number of rejection episodes (first and subsequent) limited to the first year of follow-up

\begin{tabular}{lllll}
\hline & $n$ & Episodes per 100 patients (\%) & Mean follow-up years & Episodes per 100 patient years (\%) \\
\hline Daclizumab & 11 & 22.4 & 0.85 & 26.4 \\
Control & 25 & 44.6 & 0.91 & 49.3 \\
All & 36 & 34.3 & 0.88 & 39.0 \\
\hline
\end{tabular}


The demographics for both groups were relatively equal with the Daclizumab group having a higher average PRA level and the control group having a longer follow-up period. Both these factors were taken into account by the multivariate analysis. In addition, CsA (and where applicable tacrolimus) concentrations were not different between the groups, nor were MMF or prednisone doses. There was an equal number of patients on tacrolimus in the study and the control group and the use of tacrolimus versus Neoral was also accounted for by the multivariate analysis and had no impact on the results.

The rejection rate in our control arm was very similar to the rejection rate noted for AfricanAmerican patients in the 2-g arm of the phase 3 MMF study. Therefore, it is likely that our population offers a fair representation of this high-risk group.

Hispanic patients comprise a very heterogeneous group of people, in our population. Hispanic patients had rejection rates similar to those for African-Americans (45\%) and higher than those for Caucasians (25\%). The addition of Daclizumab to this group showed the same beneficial effect as observed for the African-American group.

Daclizumab clearly increased the time to a first rejection when compared to the control group. However, there did seem to be a tendency for the Daclizumab group to have an increased number of patients suffering a first acute rejection episode after the first 6 months. This raises the possibility that the drug is merely shifting rejections over to a later time period. While this is possible, it may be more important to look at the total number of rejection episodes as opposed to patients developing rejection. If looked at in this light, the differ-

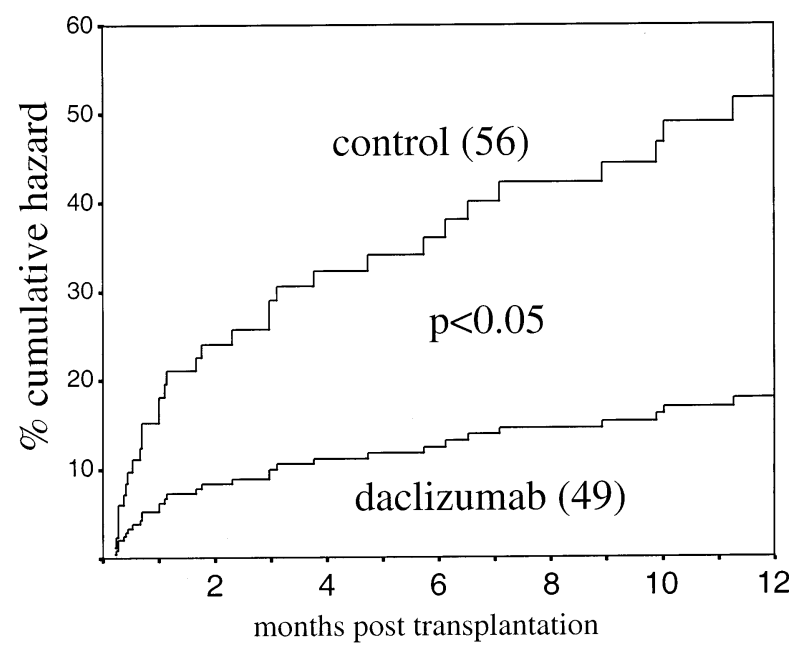

Fig. 2. Cumulative risk for a first acute rejection during the first year of follow-up by Cox proportional hazard ence in number of rejection episodes does not narrow over time. The best interpretation of these data may be that Daclizumab offers significant protection during the time of its activity and thereafter patients return to their baseline risk having been covered during the most vulnerable immunologic time period.

In summary, our study demonstrates that the addition of the IL-2 receptor antibody Daclizumab to a triple therapy regimen significantly decreases the number of rejections and number of recurrent rejection episodes in African-American and a high-risk group of Hispanic renal transplant recipients. Whether this effect will translate into better long-term graft survival will need to be addressed by a longer follow-up and a larger number of patients.

\section{References}

1. Bleyer AJ, Tell GS, Evans GW, Ettinger WhJ, BURKART JM. Survival of patients undergoing renal replacement therapy in one center with special emphasis on racial differences. Am J Kidney Dis 1996: 28: 72.

2. Katznelson S, GJertson DW, Cecka JM. The effect of race and ethnicity on kidney allograft outcome. Clin Transplant 1995: 379.

3. Vasquez EM, Benedetti E, Pollak R. Late acute rejection is more prevalent among African-American renal allograft recipients and is frequently associated with allograft loss. Transplant Proc 1998: 30: 1173.

4. The Tricontinental Mycophenolate Mofetil Renal Transplantation Study Group. A blinded, randomized clinical trial of mycophenolate mofetil for the prevention of acute rejection in cadaveric renal transplantation. Transplantation 1996: 61: 1029.

5. Rapamune Study Group, Kahan BD, Julian BA, PesCovitz MD, Vanrenterghem Y, Neylan J. Sirolimus reduces the incidence of acute rejection episodes despite lower cyclosporine doses in caucasian recipients of mismatched primary renal allografts: a phase II trial. Transplantation 1999: 68: 1526.

6. Laskow DA, Vincenti F, Neylan JF, Mendez R, Matas AJ. An open-label, concentration-ranging trial of FK506 in primary kidney transplantation: a report of the United States Multicenter FK506 Kidney Transplant Group. Transplantation 1996: 62: 900.

7. US Renal Transplant Mycophenolate Mofetil StUdy Group, Neylan JF. Immunosuppressive therapy in high-risk transplant patients: dose-dependent efficacy of mycophenolate mofetil in African-American renal allograft recipients. Transplantation 1997: 64: 1277.

8. FK506 Kidney Transplant Study Group, Neylan JF. Racial differences in renal transplantation after immunosuppression with tacrolimus versus cyclosporine. Transplantation 1998: 65: 515.

9. FK506 Kidney Transplant Study Group, Neylan JF. Effect of race and immunosuppression in renal transplantation: three-year survival results from a US multicenter, randomized trial. Transplant Proc 1998: 30: 1355.

10. Schweitzer EJ, Yoon S, Fink J, Wiland A, AnderSON L, KuO PC, LiM JW, JOHnSON LB, FARNey AC, WEIR MR, BARTLETT ST. Mycophenolate mofetil reduces 
the risk of acute rejection less in African-American than in Caucasian kidney recipients. Transplantation 1998: 65: 242.

11. Hariharan S, Alexander JW, Schroeder TJ, First MR. Outcome of cadaveric renal transplantation by induction treatment in the cyclosporine era. Clin Transplant 1996: 10: 186.

12. Light JA, Kelly JL, Aquino A, Neu L, Denavas L, Williams K. Improving renal transplant outcomes in African Americans with OKT3 induction therapy. Transplant Proc 1993: 25: 2436.

13. ANTi-Lymphocyte ANTIBODy Induction Therapy Study Group, Szczech LA, Berlin JA, Feldman HI. The effect of antilymphocyte induction therapy on renal allograft survival. A meta-analysis of individual patientlevel data. Ann Intern Med 1998: 128: 817.
14. Vincenti F, Laskow DA, Neylan JF, Mendez R, MATAS AJ. One-year follow-up of an open-label trial of FK506 for primary kidney transplantation. A report of the U.S. Multicenter FK506 Kidney Transplant Group. Transplantation 1996: 61: 1576.

15. Vincenti F, Lantz M, Birnbaum J, Garovoy M, Mould D, Hakimi J, Nieforth K, Light S. A phase I trial of humanized anti-interleukin 2 receptor antibody in renal transplantation. Transplantation 1997: 63: 33.

16. Daclizumab Triple Therapy Study Group, Vincenti F, Kirkman R, Light S, Bumgardner G, Pescovitz M, Halloran P, Neylan J, Wilkinson A, Ekberg H, GASTON R, BACKMAN L, BURDICK J. Interleukin-2-receptor blockade with daclizumab to prevent acute rejection in renal transplantation. N Engl J Med 1998: 338: 161. 